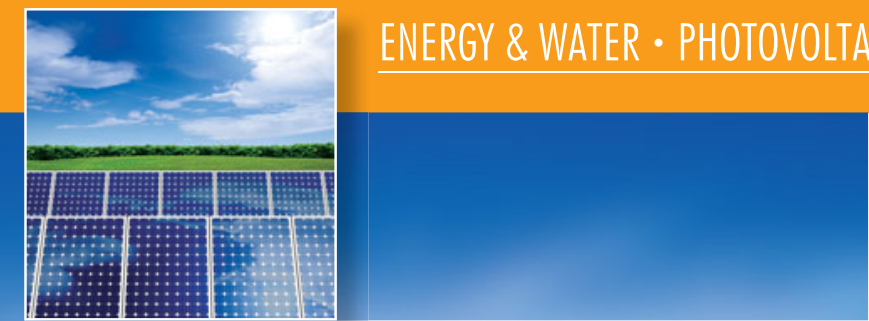

\title{
Sustainability metrics for extending thin-film photovoltaics to terawatt levels
}

\section{Vasilis Fthenakis}

Over the past 12 years, photovoltaics enjoyed an average growth of $\sim 45 \%$ per year that was affected only marginally by the recent global financial crisis. Industrial roadmaps and analysts' forecasts share visions of solar power becoming a major contributor to national and global electricity grids, with several terawatts of cumulative deployment by 2050 or earlier. For photovoltaics technology to become a major sustainable player in a competitive powergeneration market, it must provide abundant, affordable electricity, with environmental impacts dramatically lower than those from conventional power generation. This article summarizes the prospects in each of three basic aspects of sustainability, namely, system costs, environmental impacts, and resource availability, all of which are examined in the context of prospective life-cycle assessment. Indeed, these three aspects are closely related: Increasing the efficiency of material recovery by recycling spent modules will become increasingly important in resolving cost, resource, and environmental constraints on large-scale sustainable growth.

\section{Introduction}

As discussed throughout this issue, sustainable development is development that "meets the needs of the present without compromising the ability of future generations to meet their own needs."1 Photovoltaic devices, as fuel-free energy sources, are inherently sustainable unless they are too expensive to produce, are manufactured using materials that are depletable, or are environmentally unsafe.

Assessing the sustainability of continued rapid growth of photovoltaic use requires the investigation of three measurable aspects: cost, resource availability, and environmental impact. The question of cost concerns the affordability of solar energy compared to other energy sources throughout the world. Environmental impacts include local, regional, and global effects, including land use, that must be considered over a long time horizon. Finally, availability of material resources matters to current and future generations under the constraint of affordability. More concisely, photovoltaics (PV) must meet the need for generating abundant electricity at competitive costs while conserving resources for future generations and having environmental impacts lower than those of current modes of power generation and preferably also lower than those of alternative future energy options.
The challenges vary among different photovoltaic technologies. For example, first-generation crystalline-silicon photovoltaics relies on abundant silicon, but its costs are relatively high. By comparison, second-generation technologies are cheaper but less efficient. Cadmium telluride thin-film modules, for example, have the lowest production costs, but there are concerns about the availability of tellurium and the toxicity of cadmium used as a precursor to CdS and CdTe. Similarly, copper indium gallium (di)selenide (CIGS) technologies share these concerns about materials availability (i.e., gallium, indium), and some high-performance silicon technologies use potent greenhouse gases (e.g., $\mathrm{NF}_{3}$ ).

This article discusses the factors that determine whether photovoltaics can be sustainably expanded to supply a large fraction of the world's energy needs, focusing on three second-generation PV technologies: cadmium telluride (CdTe), copper indium gallium selenide (CIGS), and amorphous silicon-germanium (a-SiGe). These technologies combine reasonable efficiencies with low costs and, because they require only thin films of semiconductor material, modest materials demands. Nonetheless, each of them uses some elements (tellurium, indium and gallium, and germanium, respectively) of constrained availability that could limit their application on a large scale. Increases 
in efficiency and reductions in thin-film layer thickness will ease some of this burden, as described in Table I, which lists a range of plausible scenarios for these improvements. The most likely scenarios therein correspond to module efficiencies in 2020 of $80 \%$ of the current record cell efficiencies for each of the thin-film technologies. ${ }^{2}$

\section{Economics}

Photovoltaics currently enjoys rapid growth in a subsidized market, as many countries offer financial incentives for installing and using solar power. However, such funding will not last forever, and to be sustainable, the expense of PV power must reach parity with the direct cost of grid electricity. On the other hand, arguably, subsidies should continue on the basis that photovoltaics received much lower subsidies during its first stage of deployment than other electricity-generation technologies. ${ }^{3}$ For example, starting in the 1950 s, nuclear power in the United States garnered support worth US\$3.3 billion per year in today's dollars (viz., 1\% of the 1965 federal budget) during its first 15 years. Nuclear power plants in the United States still benefit from the Price-Anderson Act (which partially indemnifies nonmilitary nuclear facilities against liability claims arising from nuclear incidents) and cannot break ground without loan guarantees from the U.S. federal government. ${ }^{3}$ Oil and gas received an average of US\$1.8 billion per year, or $0.5 \%$ of the federal budget, in their first 15 years. ${ }^{3}$ In contrast, the total subsidies to solar and wind power averaged less than US $\$ 0.4$ billion/year (i.e., $0.01 \%$ of the current federal budget) from 1994 to $2009 .{ }^{3}$

The issue of cost and affordability demands a full accounting of the price of electricity. To its direct cost should be added the external costs assumed by society at large, such as impacts on ecosystem and human health, food supply, and land use. A recent study from the Harvard School of Public Health estimated that coal costs the U.S. public an additional US\$300-500 million annually. ${ }^{4}$ Including these damages would double or triple the price per kilowatt-hour of electricity generated from coal, making photovoltaics economically competitive.

In 2011, PV electricity from utility installations under irradiation conditions equivalent to those in the southwestern United States cost US\$0.12-0.14/kWh (alternating current). This is already competitive with peak rates for grid electricity in California but about three times more expensive than average wholesale electricity prices (Figure 1). Industry forecasts suggest that, by 2020, the expense of producing modules for

Table I. Assumptions for thin-film photovoltaic (PV) efficiencies and layer thicknesses discussed in the text.

\begin{tabular}{|c|c|c|c|c|c|c|c|c|}
\hline \multirow[t]{3}{*}{ PV type } & \multicolumn{4}{|c|}{ Efficiency (\%) } & \multicolumn{4}{|c|}{ Layer thickness $(\mu \mathrm{m})$} \\
\hline & \multirow[t]{2}{*}{2010} & \multicolumn{3}{|c|}{2020} & \multirow[t]{2}{*}{2010} & \multicolumn{3}{|c|}{2020} \\
\hline & & Conservative & Most likely & Optimistic & & Conservative & Most likely & Optimistic \\
\hline CdTe & 11.7 & 13 & 13.2 & 14 & 3 & 2.5 & 1.5 & 1 \\
\hline CIGS & 11.5 & 14 & 15.9 & 16.3 & 1.6 & 1.2 & 1 & 0.8 \\
\hline a-SiGe & 6.8 & 9 & 9.7 & 10 & 1.2 & 1.2 & 1.1 & 1 \\
\hline
\end{tabular}

\section{Emissions and disposal}

The operation of fossil-fuel-burning power plants is causing adverse health effects and increased atmospheric carbon dioxide concentrations. Although photovoltaic systems do not generate any toxic or greenhouse gases during operation, such emissions can occur during the production of the materials used for solar cells and systems. Recent assessments of the life-cycle emissions from photovoltaic systems showed that, under conditions equivalent to those in the southwestern United States, they emit about $17-39 \mathrm{~g}$ of $\mathrm{CO}_{2} / \mathrm{kWh}$, in comparison to $500-1100 \mathrm{~g}$ of $\mathrm{CO}_{2} / \mathrm{kWh}$ from fossilfuel plants and $16-55 \mathrm{~g}$ of $\mathrm{CO}_{2} / \mathrm{kWh}$ from nuclear-power plant life cycles in the United States. ${ }^{10}$ Some facilities producing tandem a-Si/multicrystalline silicon (mc-Si) cascade thinfilm or high-performance monocrystalline-silicon modules use potent greenhouse gases, such as $\mathrm{NF}_{3}$, as agents for reactor cleaning or texturing, but such agents can be replaced or their emissions abated.

Similarly to greenhousegas emissions, releases of 


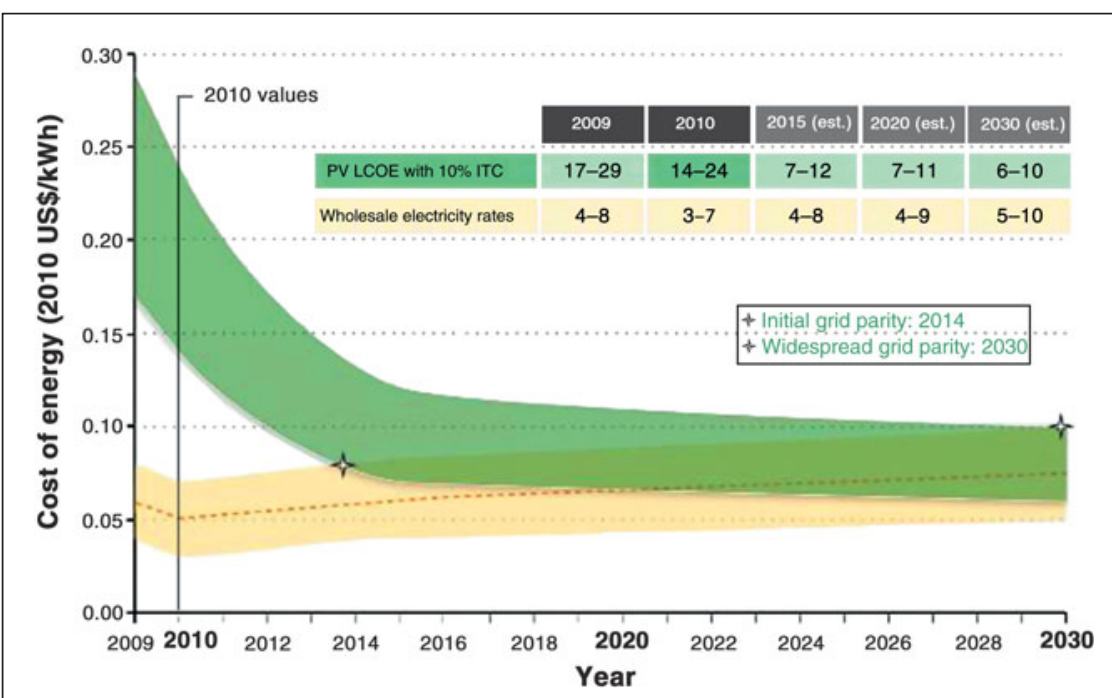

Figure 1. Projections of levelized costs of energy (LCOE) for utility-scale photovoltaic electricity and grid electricity in the United States, assuming a 10\% investment tax credit (ITC) for photovoltaics. The width of the photovoltaics (green) band reflects the differences between high (Phoenix, AZ) and low (New York) solar radiation levels and between low $(8.2 \%)$ and high (9.9\%) financing interest rates. The vertical line at 2010 denotes rates at the time of the analysis, and the crosses show when the two electricity sources will become cost-competitive for some conditions (left cross) and for typical conditions (right cross). (Reproduced from Reference 5 courtesy of the U.S. Department of Energy.) procedure (TCLP), ${ }^{14}$ which simulates the leaching of wastes, substantiates module safety under controlled conditions. Emissions of cadmium from current-vintage double-glass photovoltaics were shown to be extremely small. ${ }^{14} \mathrm{Nev}$ ertheless, there could be other pathways for uncontrolled releases in extreme situations, and therefore, every effort should be made to collect the modules and recycle the contained metals at the end of their useful lifetimes. The greatest challenge might lie in ensuring a high recovery rate of spent modules from dispersed residential installations. Also, the cost of infrastructure for both collection and recycling must be optimized to ensure affordability. Processes for separating polymeric materials such as ethylene vinyl acetate from glass must be improved so that the purity of recovered glass is sufficient for reuse in soda-lime glass manufacturing. Estimates of residual risks should be compared with the risks inherent over the life cycles of alternative systems and of conventional power-generation systems that photovoltaics would replace. Toxic emissions are much lower in the life cycle of thin-film photovoltaics than in the life cycles of alternative photovoltaic and conventional power systems. ${ }^{13}$ priority pollutants (e.g., $\mathrm{SO}_{2}, \mathrm{NO}_{x}$, particulates) from photovoltaic life cycles comprise only $2-4 \%$ of those from fossil-fuel plants. Heavy-metal emissions deserve special consideration, as certain thin-film solar cells use such metals (e.g., cadmium in CdTe and CdS, selenium in CIGS). An experimental investigation of the potential for liberating cadmium from solar cells during residential fires demonstrated that 99.5-99.96\% of the cadmium would be safely encapsulated in the molten glass. ${ }^{11}$ Direct cadmium emissions in the life cycle of CdTe solar cells amount to $0.016 \mathrm{~g}$ per gigawatt-hour of energy produced under average U.S. conditions. ${ }^{11}$ On the other hand, a typical coal-burning plant in the United States, equipped with electrostatic precipitators or baghouses (fabric filters) operating at $98.6 \%$ cadmium removal efficiency, emits $2 \mathrm{~g}$ of cadmium per gigawatt-hour. ${ }^{12}$ Replacing grid electricity with PV systems would result in $89-98 \%$ reductions in the emissions of greenhouse gases, criteria pollutants, heavy metals, and radioactive species. ${ }^{13}$

Although these results offer a comparative picture of the environmental benefits from employing thin-film photovoltaics, the potential risks from PV modules at the end of their useful life merit further discussion. For example, there are concerns about the cadmium and selenium components in CdTe and CIGS/CdS thin-film solar cells. However, the potential for harm to humans or the environment is related not to the quantity of toxic compounds in a module but rather to their potential for leaking out. Release scenarios that have been tested include leaching from modules abandoned in landfills and emissions during fires. The first problem, addressed by the toxicity characteristic leaching

\section{Material use}

The availability of materials for very large growth in the use of photovoltaics is of some concern. (For an overview of metal element availability, see the article by Graedel et al. in this issue.) A recent European Commission report ${ }^{15}$ lists four elements as critical in terms of supply risk and economic importance to the European Union markets: germanium, gallium, indium, and tellurium. A U.S. DOE report focusing on U.S. and global markets also deems the last three as critical, but does not include germanium. ${ }^{16}$ Indium is considered as having the highest short-term criticality in the DOE report.

Most sources agree that gallium, indium, and tellurium use in photovoltaics will increase because the entire PV industry is experiencing high growth. Furthermore, beyond photovoltaics, the usage of gallium in integrated circuits and optoelectronics and of indium in flat-panel displays is expected to rise.

These materials are limited in supply because they are minor byproducts of aluminum, zinc, copper, and lead production; accordingly, their production is inherently linked to that of the base metals, and thus, the rate of production of these base metals must be examined. The energy to extract the elements might pose an additional limitation. (See the article in this issue by Lubomirsky and Cahen.)

\section{Base metals: Copper, zinc, lead, and aluminum}

Copper is the parent metal for tellurium; zinc for indium, germanium, and gallium; lead for tellurium, cadmium, and indium; and aluminum for gallium. The demand for copper is expected 
to reach a peak within 50 years, and those for zinc and lead are expected to peak in $\sim 20$ years, whereas the demand for aluminum is forecasted to increase through the end of the century. ${ }^{17-19}$ The U.S. Geological Survey ${ }^{20,21}$ predicted a rate of growth in global demand for copper of 3.1\% per year between 2000 and 2020; so far, this prediction has been correct. Although primary production in the world's metal smelters fluctuates highly, ${ }^{22}$ the average production is in line with the average demand. Forecasts beyond 2020 are less certain. Ayres et al. ${ }^{18}$ developed eight scenarios of future demand and growth rates for both primary and secondary production of copper until 2100 , based on the economic growth models of the International Panel on Climate Change. Their model predicts a peak in copper production in 2050-2055; thereafter, demand is expected to decrease gradually or remain about constant during the rest of the $21 \mathrm{st}$ century, as the role of recycling becomes more significant. Zinc extraction grew by $3.2 \%$ annually between 1910 and 2002, and this trend has continued over the past 10 years. ${ }^{23,24}$ The growth in demand for zinc through 2030 is assumed to be the same as that for copper.

\section{Tellurium}

The assessment of tellurium resources is debatable. ${ }^{25-27}$ The main sources of tellurium are the anode slimes from copper electrorefining operations, for which global tellurium recovery rates of $33-40 \%$ have been estimated. In contrast, the recovery rate of copper from the same ores was $80 \%$ or better, and that of gold was over $95 \%$. Evidently, the market drives the rate of recovery, with a higher demand and price justifying additional processing. Nothing inherently prevents recovery rates for tellurium from being as high as those for copper, or perhaps even gold, provided that the price is sufficiently high. (Indeed, the concentration of gold in anode slimes typically is lower than that of tellurium.) However, there is a limit to the price of tellurium that will sustain affordable CdTe photovoltaics. At US\$200/kg, the tellurium currently used in CdTe modules is $\sim \mathrm{US} \$ 0.03 / \mathrm{W}_{\mathrm{p}}$; it will fall to US\$0.01/ $\mathrm{W}_{\mathrm{p}}$ when the module efficiency increases to $13.2 \%$ and the thickness of the CdTe layer drops to $1.5 \mu \mathrm{m}$. Thus, tellurium prices up to 5-10 times higher than current levels might not affect the goal for module production of US\$0.50-0.70/ $\mathrm{W}_{\mathrm{p}}{ }^{2}$

Several scenarios are suitable for assessing the future availability of tellurium. All are related to projected copper production because, with very few exceptions, the quantities and prices of the minor metals do not warrant the extraction and processing of ores without the simultaneous recovery of copper. Starting with the tellurium content in copper anodes of $1250 \mathrm{t} / \mathrm{yr}$ and assuming $3.1 \%$ annual growth and a gradual increase to $80 \%$ recovery from anode slimes, by 2020, the annual primary production of metallurgical-grade tellurium would be $1450 \mathrm{t} / \mathrm{yr}$. In line with this estimate, the U.S. DOE forecasts $1220 \mathrm{t}$ of tellurium production in 2015 . $^{16}$

In addition to tellurium from copper mines, there are other types of smaller reserves, including tellurium-rich mineral deposits in China and Mexico from which the near-term direct mining of tellurium is economically feasible. Over the longer term, tellurium recovery from mining tailings and from refining of lead-zinc ores is also possible. In addition, massive resources of tellurium exist in ocean-floor ferromanganese nodules, reportedly as much as nine million tonnes at mean concentrations of $50 \mathrm{ppm} .{ }^{28}$ However, because quantitative information is not available for the former and because the recovery of metals from deep ocean is not currently cost-efficient, these resources were not included in the current analysis.

Presently, about $42 \%$ of tellurium (based on 2006 production) is used in iron and steel, and $23 \%$ is used in chemicals; recycling of tellurium from these products is not currently practiced. However, the tellurium content in CdTe modules is relatively high ( $\sim 500 \mathrm{ppm})$, so that end-of-life modules are the obvious choice for extracting and recovering scarce metals. The technical and economic feasibility of recycling CdTe solar cells is well confirmed. Small-scale operations have achieved $99.99 \%$ separation of tellurium and cadmium from end-of-life modules at an estimated cost of US $\$ 0.02 / \mathrm{W}_{\mathrm{p}}$. On an industrial scale, a $90 \%$ overall recovery rate is expected. ${ }^{29}$

At the module level, with economic incentives and laws regulating disposal, the collection of spent modules can be expected to reach $100 \%$ from large utility installations and $80 \%$ from residential installations. Accordingly, after 2045, recycling will become an increasingly significant source of secondary tellurium (Figure 2). This evaluation is incorporated into material constraints on CdTe PV growth.

\section{CdTe PV production}

Under these assumptions, the total annual production of CdTe photovoltaics that tellurium availability in copper smelting can support is constrained to $16-24 \mathrm{GW}_{\mathrm{p}}$ in $2020,44-106 \mathrm{GW}_{\mathrm{p}}$ in 2050, and 60-161 GW in 2075 (Figure 3a). The telluriumbased limit of cumulative global production of CdTe photovoltaics (Figure 3b) is $120 \mathrm{GW}_{\mathrm{p}}$ by 2020 , rising to $0.9-1.8 \mathrm{TW}_{\mathrm{p}}$

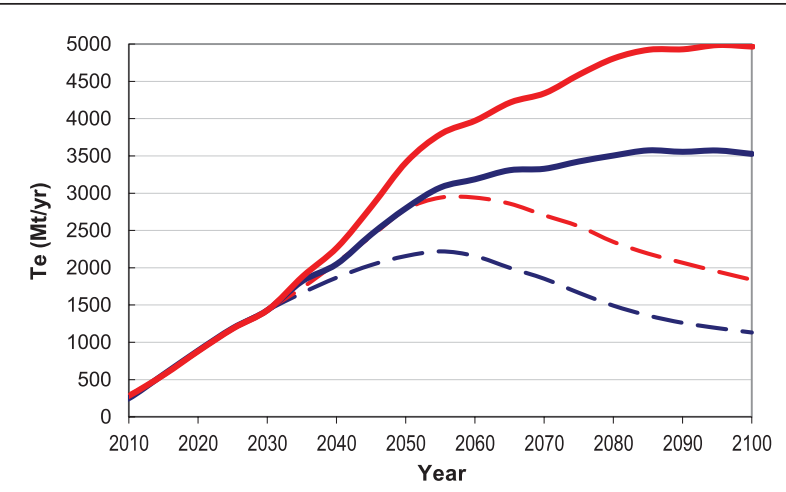

Figure 2. Projections of tellurium availability for photovoltaics from copper smelters (dashed lines; peaking in 2055 ) and total from copper smelters and recycling of end-of-life photovoltaic modules (solid lines; continuing upward trend until 2095). The red and blue curves in each pair correspond to high and low projections, respectively. Note: A tellurium demand of $322 \mathrm{t} / \mathrm{yr}$ for non-photovoltaic uses was subtracted. Reproduced from Reference 30 courtesy of Brookhaven National Laboratory. 


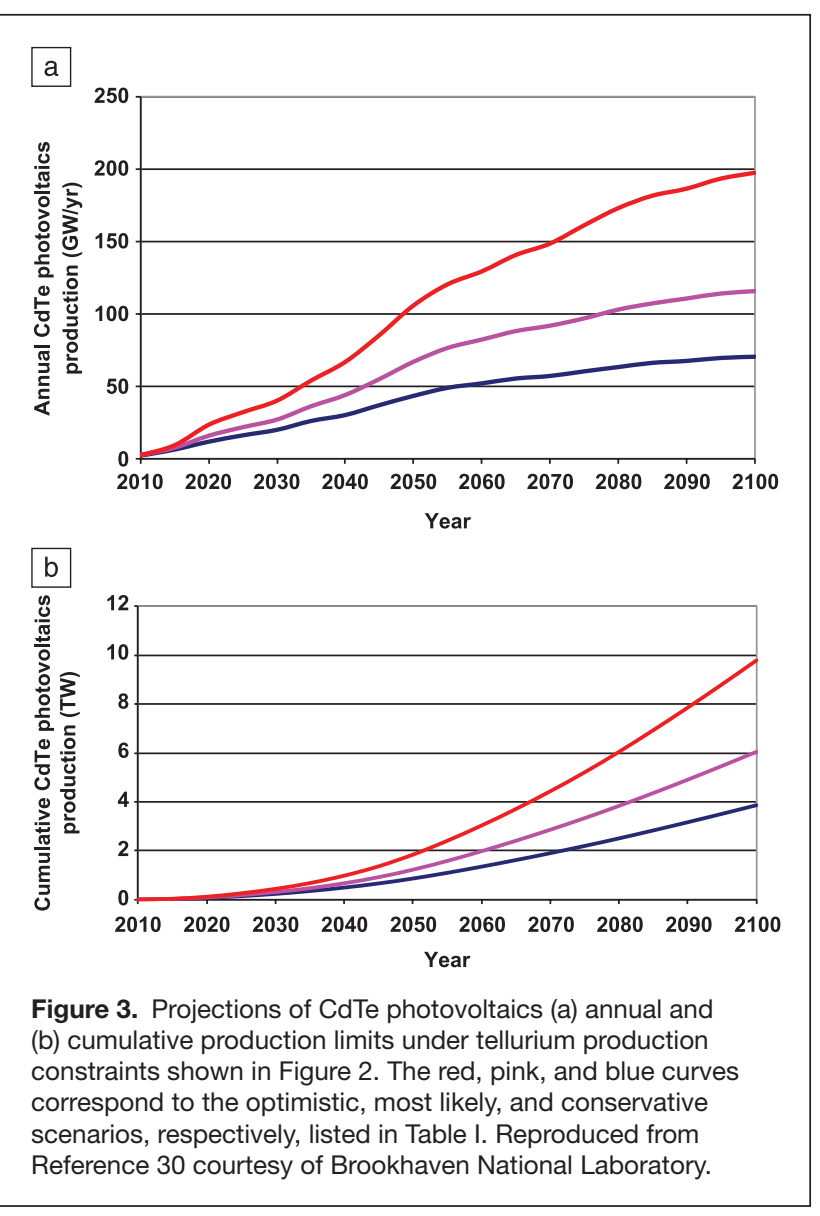

by 2050 and $3.8-10 \mathrm{TW}_{\mathrm{p}}$ by 2100 . These limits are based strictly on tellurium coproduction during copper production from known resources and do not include the potential for direct mining or the discovery of additional resources.

For the production of CdTe photovoltaics to continue growing by $40 \%$ per year, tellurium recovery from anode slimes must increase to $80 \%$, for which there is already a technological basis. In addition, the CdTe film thickness must decrease by a factor of two from the current thickness of films formed by vaportransport deposition, as assumed in the "most likely" scenario in Table I, which will require additional research and engineering.

\section{Indium}

The supply of indium is tied to the production of zinc and is likely to remain so in the future. The price of indium reached a high of US $\$ 1,000 / \mathrm{kg}$ in 2005, but is currently about US\$600/kg. In 2010, the estimated production of indium was $1345 \mathrm{t}$, of which $480 \mathrm{t}$ came from mining and another $865 \mathrm{t}$ came from recycling of used indium sputtering targets. The main use of indium today is in liquid-crystal displays (LCDs), accounting for $65 \%$ of current consumption; photovoltaics uses an estimated $5 \%$ of the primary production of indium. Competing applications of indium present extra challenges to PV growth, and further, its recovery from the zinc circuit is already high
( 70-80\%), leaving little room for enhancement. The estimated production for 2015 is only $1612 \mathrm{t}$, a large fraction of which is expected to be used in LCDs.

\section{Gallium}

Most gallium is produced as a byproduct of treating bauxite ore to extract aluminum; about $10 \%$ originates in sphalerite, and it is produced during the purification stages of the zinc production circuit. The world resources of gallium in bauxite ore are estimated to be about one million tonnes, but evaluations of the reserves (deposits that currently can be mined economically) are lacking. Most gallium is extracted electrolytically from a solution of crude aluminum hydroxide in the Bayer process for producing alumina and aluminum. In 2010, the production of gallium was estimated to be $207 \mathrm{t}$, of which $100 \mathrm{t}$ was derived from mining and the rest from recycling scrap. ${ }^{16,31}$ Only $~ 10 \%$ of alumina producers extracted gallium, with the others not finding it economical. The price of gallium reached a peak of US\$2,500/kg in early 2015 and is currently US\$500-600/kg. Presently, almost all of the gallium produced is used in integrated circuits $(67 \%)$ and optoelectronics (31\%), with both usages exhibiting upward trends. ${ }^{19}$ The estimated 2015 supply is $325 \mathrm{t}$.

\section{CIGS production}

Under the listed assumptions on indium and gallium availability, the material-constrained growth potential of CIGS photovoltaics has been calculated as $13-22 \mathrm{GW}_{\mathrm{p}} / \mathrm{yr}$ in 2020 , $17-106 \mathrm{GW}_{\mathrm{p}} / \mathrm{yr}$ in 2050 , and $17-152 \mathrm{GW}_{\mathrm{p}} / \mathrm{yr}$ in $2075 .^{2}$ These estimates assume $80 \%$ extraction recoveries and use of only $50 \%$ of the growth in the supply of indium for CIGS photovoltaics, as well as improvements in module efficiency and material requirements, as shown in Table I. Note that the estimates for midcentury and beyond are based on the presumption that the growth of zinc extraction will follow that of copper; this is questionable because the depletion time of zinc might be shorter than that of copper. Furthermore, recovering indium and gallium from CIGS is more challenging than recouping tellurium from $\mathrm{CdTe}$, as their respective concentrations are lower and their separations are more difficult.

\section{Germanium}

Zinc mineral deposits are also the main source for germanium. In 2006 , germanium production was estimated to be $\sim 100 \mathrm{t}$. Estimates of germanium availability carry higher uncertainty than those for indium because of the dearth of resource data for germanium.

\section{a-SiGe production}

The germanium-related constraints of amorphous silicongermanium (a-SiGe) photovoltaics are estimated to be 3-11 $\mathrm{GW}_{\mathrm{p}} / \mathrm{yr}$ in 2020 , 5-49 $\mathrm{GW}_{\mathrm{p}} / \mathrm{yr}$ in 2050 , and $10-120 \mathrm{GW}_{\mathrm{p}} / \mathrm{yr}$ in 2100 (Table II). Tellurium, gallium, and indium cannot be replaced in current technologies because of their particular functions. However, germanium can be superseded by nanostructured layers of mc-Si and in tandem a-Si/mc-Si cascade thin-film modules. 


\begin{tabular}{|l|c|c|c|c|c|c|c|}
\hline \multicolumn{2}{|c|}{ Table II. Limits on annual production of various thin-film photovoltaic (PV) technologies due to constraints } \\
of metal availability.
\end{tabular}

${ }^{a}$ Estimates based only on coproduction with copper; direct tellurium mining is not included.

\section{Conclusions}

Current-generation thin-film PV technologies (i.e., CdTe, CIGS, and a-SiGe) use elements (i.e., tellurium, indium, gallium, and germanium) whose availabilities are constrained by the rates of production of the corresponding base metals (i.e., copper, zinc, and aluminum). Nevertheless, such coproduction is sufficient for each of the thin-film technologies to continue its current growth rate (i.e., $\sim 40-50 \% / y r$ ) through 2020. Aggressive scenarios of continuing high growth rates to midcentury prescribe $2.8 \mathrm{TW}$ by 2050 for the United States, to support $70 \%$ electricity generation from renewable energy for current uses and hybrid plug-in electric cars. ${ }^{8}$ A global plan of the same proportions will need at least three times more capacity. A single thin-film PV technology might not achieve this goal, but it can be supported by a combination of the three PV technologies discussed herein.

Photovoltaics are following a path of cost reduction and market growth that should enable them to become major players in global energy markets, providing terawatts of renewable energy. The sustainability of very large scales of market penetration, however, depends on cost, resource availability, and potential environmental impacts. It is likely that target costs will make photovoltaics cost-competitive in large parts of the world, but for this to happen, incentives that open new markets should remain in place. A full accounting of the cost of electricity that includes externalities shows that photovoltaics is already cost-competitive with coal in the United States. The issue of land resources is even less problematic: During their life cycles, PV technologies often use less land than the conventional power-generation systems they displace, and they are not constrained by the large consumption of water that thermoelectric power generation requires.

The availability of some elements employed in thin-film PV technologies (i.e., gallium, germanium, indium, and tellurium) is constrained by the annual production of the corresponding base metals. Among these, indium apparently has the greatest criticality in the short and medium terms. Increases in the production of tellurium to sustain the dynamic growth of CdTe photovoltaics appear to be in place, as the leading company is investing in direct mining of tellurium that can increase its availability in the near term. Materials-related sustainability deficits will be eased with enhanced recovery during primary production, reductions of the thickness of semiconductor layers, increases in the efficiency and life expectancy of modules, and recycling of spent modules. Recycling is especially important as it pertains to the three basic sustainability criteria (i.e., low cost, resource availability, and minimum environmental impact): it will lower the cost of materials while increasing their supply and resolving environmental concerns associated with end-of-life modules. Thus, current PV technologies appear to be sustainable in very large growth scenarios, supporting the cumulative deployment of several terawatts by midcentury or earlier.

\section{References}

1. Report of the World Commission on Environment and Development: Our Common Future (Annex to Document A/42/427, Oxford University Press, Oxford, UK, 1987). 2. V. Fthenakis, Renewable Sustainable Energy Rev. 13, 2746 (2009).

3. N. Pfund, B. Healey, "What Would Jefferson Do? The Historical Role of Federal Subsidies in Shaping America's Future" (DBL Investors, San Francisco, CA, September 2011).

4. P. Epstein, J. Buonocore, K. Eckerle, M. Hendryx, M. Benjamin, B. Stout III, R. Heinberg, R. Clapp, B. May, N. Reinhart, M. Ahern, S. Doshi, L. Glusstrom, Ann. N.Y. Acad. Sci. 1219, 73 (2011).

5. J. Lushetsky, paper presented at the 25th European Photovoltaics Conference, Valencia, Spain, 3-8 September 2010.

6. World Energy Assessment Overview: 2004 Update (United Nations Development Programme, New York, 2004).

7. "SunShot Initiative: Solar Program Highlights" (U.S. Department of Energy, Washington, DC), www1.eere.energy.gov/solar/sunshot/highlights.html (accessed 8 February 2012)

8. V. Fthenakis, J. Mason, K. Zweibel, Energy Policy 37, 387 (2009)

9. V.M. Fthenakis, H.C. Kim, Renewable Sustainable Energy Rev. 13, 1465 (2009). 10. V.M. Fthenakis, H.C. Kim, Energy Policy, 35, 2549 (2007).

11. V. Fthenakis, Renewable Sustainable Energy Rev. 8, 303 (2004).

12. V.M. Fthenakis, M. Fuhrmann, J. Heiser, A. Lanzirotti, J. Fitts, W. Wang, Prog. Photovoltaics Res. Appl. 13, 713 (2005).

13. V.M. Fthenakis, H.C. Kim, E. Alsema, Environ. Sci. Technol. 42 (6), 2168 (2008). 14. V. Fthenakis, Regulations on Photovoltaic Module Disposal and Recycling (Informal Report BNL-68142, Brookhaven National Laboratory, Upton, NY, 2011). 15. Critical raw materials for the EU, Report of the Ad-hoc Working Group on defining critical raw materials (European Commission, Brussels, Belgium, 2010). 16. Critical Materials Strategy (U.S. Department of Energy, Washington, DC, December 2010)

17. A. Kapur, Futures 37, 1067 (2005).

18. R.U. Ayres, L.W. Ayres, I. Råde, The Life Cycle of Copper, its Co-Products and By-Products (Mining, Minerals and Sustainable Development Working Paper no. 24, International Institute for Environment and Development, London, 2002).

19. T.E. Graedel, Annu. Rev. Mater. Res. 41, 323 (2011).

20. D.W. Menzie, D.A. Singer, J.J.H. DeYoung, in Scarcity and Growth Revisited, D.R. Simpson, M.A. Toman, R.U. Ayres, Eds. (Resources for the Future, Washington, DC, 2005), pp. 142-154.

21. D.W. Menzie, Congressional Testimony before the Committee on Resource, Subcommittee on Energy and Mineral Resources (U.S. Geological Survey, Reston, VA, 2006).

22. "Forecast 2008-2009" (Press release, International Copper Study Group, Lisbon, Portugal, 8 October 2008).

23. R.B. Gordon, M. Bertram, T.E. Graedel, Proc. Natl. Acad. Sci. U.S.A. 103, 1209 (2006). 24. "Indium," in 2006 Minerals Yearbook (U.S. Geological Survey, Reston, VA, 2007). 25. C. Wolden, J. Kurtin, J. Baxter, I. Repins, S. Shaheen, J. Torvik, A. Rockett, V. Fthenakis, E. Aydil, J. Vac. Sci. Technol. A 29 (30), 30801 (2011).

26. M.A. Green, Prog. Photovoltaics Res. Appl. 14, 743 (2006).

27. K. Zweibel, Science 328, 699 (2010).

28. J.R. Hein, A. Koschinsky, A.N. Halliday, Geochim. Cosmochim. Acta 67 (6), 1117 (2003).

29. V.M. Fthenakis, W. Wang, Prog. Photovoltaics Res. Appl. 14, 363 (2006).

30. V. Fthenakis, paper presented at the 35th IEEE Photovoltaic Specialists Conference, Honolulu, HI, 20-25 June 2010.

31. "Gallium," in 2006 Minerals Yearbook (U.S. Geological Survey, Reston, VA, 2007). 